\title{
GASTO SUBNACIONAL, PRESUPUESTADO Y EJERCIDO: LA BRECHA ENTRE EL PLAN Y LA PRÁCTICA EN MÉXICO (2003-2016)
}

\author{
SUB-NATIONAL EXPENDITURE, BUDGETED \\ AND SPENT: THE GAP BETWEEN PLAN \\ AND PRACTICE IN MEXICO (2003-2016)
}

\section{LES DÉPENSES SUBÉTATIQUES, LE BUDGET APPROUVÉ ET LE BUDGET DÉPENSÉ: LE FOSSÉ ENTRE LE PROJET ET LA PRATIQUE AU MEXIQUE (2003-2016)}

\author{
José Said Sánchez Martínez \\ El Colegio de Jalisco, A.C. \\ conocimiento.123@gmail.com
}

RESUMEN: Hasta ahora, los estudios no han prestado suficiente atención a la diferencia entre el gasto público presupuestado y el monto ejercido en los gobiernos estatales en México. En consecuencia, esta investigación tiene dos objetivos: presentar evidencia sobre esta brecha durante el periodo 20032016 y, mediante un análisis para datos tipo panel (panel corrected standard errors), determinar si la alineación partidista en forma vertical incide en su comportamiento. Los resultados muestran que la diferencia entre lo presupuestado y lo ejercido es una práctica común, específicamente como sobreejercicios y que, en contextos de gobierno dividido en forma vertical, este monto es mayor.

Palabras clave: presupuesto, gasto ejercido, gasto neto ejercido, gobierno dividido vertical, gobierno unificado vertical.

Abstract: To date, studies have paid little attention to the difference between budgeted public expenditure and the amounts actually spent by state governments in Mexico. As a result, this investigation has two goals: to present evidence about this gap for the period 2003-2016, and to use a panel corrected standard errors analysis to determine if vertical alignment of political parties has an impact on their behavior. The results show that the difference between what is budgeted and what is spent is a common practice, particularly in the 
form of overspends, and in contexts of vertically divided government this amount tends to be higher.

Keywords: budget, expenditure spent, net expenditure spent, vertically divided government, vertically unified government.

\section{Traducción de Gonzalo Celorio Morayta}

RÉsumé : Jusqu'à présent, les recherches n'ont pas prêté assez d'attention à l'écart entre le budget approuvé et les dépenses réelles des gouvernements subétatiques au Mexique. Notre travail vise le double but de mettre en évidence ce phénomène durant la période 2003-2016 et, moyennant l'analyse des données individuelles temporelles (panel corrected standard errors), d'établir si le fait que des représentants d'un même parti gouvernent aux niveaux subétatique et national a des effets ou non sur le comportement analysé. Nos résultats montrent que la différence entre le budget approuvé et le budget dépensé est fréquente, car le second dépasse souvent le premier, et que les déficits sont plus considérables lorsque des fonctionnaires issus de partis différents exercent le pouvoir dans ces deux domaines.

Mots clefs: Budget, dépenses réelles, budget net dépensé, gouvernement divisé sur le plan vertical, gouvernement unifié sur le plan vertical.

Traducción de Bernardo Mabire

Fecha de recepción: febrero de 2018

Fecha de aceptación: junio de 2019 


\section{INTRODUCGIÓN}

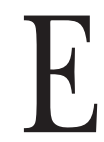

n los últimos años, el estudio del gasto público en México ha tomado relevancia en la academia y la opinión pública. El gasto público es la política más importante de un gobierno, ya que en él se determinan los recursos que se destinarán a los distintos programas, políticas públicas y proyectos. Sin embargo, hasta ahora no se ha puesto suficiente atención a la diferencia entre lo que se presupuesta y lo que, en efecto, se ejerce. Cabe señalar que este aspecto se considera uno de los Objetivos de Desarrollo Sostenible de la Organización de las Naciones Unidas (ONU), específicamente el denominado Paz, justicia e instituciones sólidas. En éste se incluye el indicador "Gasto del gobierno como proporción del presupuesto original aprobado", sobre el que se destaca que para "ofrecer una base sólida para el desarrollo, los presupuestos de los gobiernos deben ser exhaustivos, transparentes y realistas". ${ }^{1}$ Asimismo, el Programa de Gasto Público y Rendición de Cuentas (PEFA) ${ }^{2}$ considera esta variable en sus evaluaciones internacionales sobre el manejo de las finanzas públicas. ${ }^{3}$ Una diferencia entre lo presupuestado y lo aprobado mayor a $+-15 \%$ con respecto a aquél se considera una mala práctica.

La evidencia que se tiene para el caso del gobierno federal en México indica que, generalmente, se gasta más de lo

${ }^{1}$ Naciones Unidas, Informe de los Objetivos de Desarrollo Sostenible 2017, Nueva York, ONU, 2017, p. 52, https://unstats.un.org/sdgs/files/report/ 2017/TheSustainableDevelopmentGoalsReport2017_Spanish.pdf (consulta de mayo de 2018).

2 El PEFA es una asociación de donantes creada en 2001, integrada por el Banco Mundial, la Comisión Europea, el Fondo Monetario Internacional y diversos gobiernos europeos.

${ }^{3}$ Programa de Gasto Público y Rendición de Cuentas (PEFA), Marco de referencia para la evaluación de la gestión de las finanzas públicas, 2016, Washington, D.C., 2016. https://pefa.org/resources/pefa-2016-marco-de-referencia-para-la-evaluacion-de-la-gestion-de-las-finanzas-publicas (consulta de mayo de 2018). 
que la Cámara de Diputados aprueba en el Presupuesto de Egresos de la Federación (PEF), es decir, que lo establecido en el PEF no tiene una correspondencia con la práctica. ${ }^{4}$ Los datos muestran que, entre 2000 y 2016, la magnitud del gasto adicional a lo presupuestado fue de 4.1 billones de pesos, equivalente a $86 \%$ del gasto programado del gobierno federal para $2017 .{ }^{5}$ En promedio, entre 2000 y 2016 , el gobierno ejerció $7 \%$ más gasto del establecido en el PEF. ${ }^{6}$ Para tener puntos de comparación, de acuerdo con los estudios realizados por el PEFA, en Colombia la diferencia promedio entre el gasto presupuestado y el ejercido ha sido de $7 \%$, y en Brasil de $-5.8 \% .^{7}$

La diferencia entre lo presupuestado y lo ejercido da cuenta de diferentes problemáticas: el poder ejecutivo tiene un amplio margen de maniobra para modificar el presupuesto; el gasto que aprueba el poder legislativo no se respeta; los presupuestos son poco confiables, debido a que sufren modificaciones durante su ejercicio; no hay mecanismos que permitan controlar y dar certidumbre al proceso de ejecución del gasto; el presupuesto no se elabora considerando el gasto de

${ }^{4}$ A. Díaz-Cayeros y B. Magaloni, "Autoridad presupuestal del poder legislativo en México: una primera aproximación”, Política y Gobierno, vol. 5, núm. 2 (1998), pp. 503-528; México Evalúa, Descifrando la caja negra del gasto, México, México Evalúa, 2014; México Evalúa-cidac, Léase si quiere gobernar (en serio), México, México Evalúa- CIDAC, 2018; L. Nuñez, ¿̨Y dónde quedó la bolita? Presupuesto de Egresos ficticio, México, Aguilar, 2017; C. Ugalde (coord.), La negociación política del presupuesto en México 1997-2012, MéxiCO, EDIMPRO-SITESA, 2014.

${ }^{5}$ L. Núñez, Loc. cit.

${ }^{6}$ Una parte de este gasto adicional ha sido posible gracias a una subestimación de los ingresos que se espera obtener, lo cual también es una práctica recurrente. Véase México Evalúa, op. cit.

${ }^{7}$ Programa de Gasto Público y Rendición de Cuentas, Evaluación PEFA Colombia 2015. Desempeño de la Gestión de las Finanzas Públicas, 2016, https:/ / pefa.org/country/colombia (consulta de mayo de 2018); Programa de Gasto Público y Rendición de Cuentas, Federal Public Financial Management Performance. Base on the PEFA Methodology, 2009, https://pefa.org/country/ brazil (consulta de mayo de 2018). 
años previos; el poder legislativo tiene un papel débil durante el ejercicio del gasto, entre otros. ${ }^{8}$

A nivel estatal, las investigaciones sobre el gasto público han aumentado de manera importante. Los estudios se han enfocado desde en temas generales, como el gasto, ${ }^{9}$ hasta en cuestiones más específicas, como la deuda pública, ${ }^{10}$ la dependencia financiera, ${ }^{11}$ el gasto particularista ${ }^{12}$ y el desvío de los recursos públicos. ${ }^{13}$ No obstante, el análisis ha abordado sólo el presupuesto o bien el gasto ejercido, sin

${ }^{8}$ Loc. cit.; México Evalúa-cidac, op. cit; L. Núñez, op. cit.

${ }^{9}$ R. Ramírez y A. Erquizio, "Análisis del ciclo político electoral a partir de variables de gasto público por entidad federativa en México, 19932009”, Paradigma económico, vol. 4, núm. 2 (2012), pp. 5-27; C. Velázquez, "Determinantes del gasto estatal en México", Gestión y Política Pública, vol. 15, núm. 1 (2006), pp. 83-108.

${ }^{10}$ Auditoría Superior de la Federación, Análisis de la deuda pública de las entidades federativas y municipios, México, Cámara de Diputados, 2011; C. Carpizo, "Los efectos cruzados de la competencia política sobre el endeudamiento: un análisis empírico de la deuda estatal en México, 2003-2010”, trabajo presentado en el Premio Nacional de Finanzas Públicas 2012, Cámara de Diputados, 2012; M. Kinto, “¿Por qué se endeudan los gobiernos estatales en México? Algunas consideraciones para la reforma constitucional y la ley reglamentaria en materia de responsabilidad hacendaria”, Premio Nacional de Finanzas Públicas 2014, Ciudad de México, Cámara de Diputados, 2014; O. Montemayor, "Determinantes del endeudamiento subnacional. Un estudio para los estados y municipios de México, 19931999”, Ensayos, vol. 22, núm. 1 (2003), pp. 35-88; R. Tépach, "La deuda pública de las entidades federativas explicada desde la perspectiva del federalismo mexicano”, documento de trabajo, Cámara de Diputados, 2012, http:/ / www.diputados.gob.mx/sedia/sia/se/SAE-ISS-17-12.pdf (consulta de mayo de 2018); R. Tépach, "El flujo de deuda pública de las entidades federativas de México analizado desde el enfoque del federalismo fiscal”, documento de trabajo, Cámara de Diputados, 2015, http:/ / www.diputados. gob.mx/sedia/sia/se/SAE-ISS-15-15.pdf (consulta de mayo de 2018).

${ }^{11} \mathrm{~J}$. Ibarra, "Entorno político y dependencia financiera de los estados mexicanos”, Gestión y Política Pública, vol. 22, núm. 1 (2013), pp. 3-44.

${ }^{12}$ M. Armesto y J. Olmeda, "Oposición legislativa y patronazgo político. Gasto en empleo público de los estados en México”, Región y Sociedad, núm. 71 (2018), pp. 1-27.

13 N. Roldán, M. Castillo y M. Ureste, La estafa maestra. Graduados en desaparecer el dinero público, México, Planeta, 2018. 
considerar la diferencia entre ambos, es decir, entre el presupuesto aprobado y el ejercido al final del año. Debido a los datos mostrados en el caso federal, es preciso preguntarse qué es lo que ocurre a nivel subnacional.

Uno de los pocos estudios que ha analizado la brecha entre el presupuesto y el gasto ejercido es el del Instituto Mexicano para la Competitividad (IMCO). Gracias a éste se sabe que, en el ejercicio fiscal 2016, los estados erogaron más de lo que habían presupuestado: en promedio, $14 \% .{ }^{14}$ En un análisis anterior, se identificó que entre 2006 y 2008 hubo un sobreejercicio promedio de $24 \% .{ }^{15}$ Los estudios en otros países son escasos, pero cabe mencionar la información disponible para algunas provincias de Argentina, en donde se han detectado diferencias entre el 15.8 y el $18.9 \% .^{16}$

A pesar del valioso aporte de estos datos, no se cuenta con un análisis sistemático y temporal más amplio que permita saber si esta conducta es la regla o la excepción. Además, al ser México una república federal, no se ha indagado si la alineación partidista en forma vertical afecta su comportamiento. En consecuencia, son pertinentes las siguientes preguntas: ¿cuál es la magnitud de la diferencia entre lo presupuestado y lo ejercido en los estados?, ¿cómo se distribuye esta diferencia tanto transversal como longitudinalmente?, ¿qué variables político partidistas influyen en su comportamiento?

${ }^{14}$ Instituto Mexicano para la Competitividad (IMCO), "Índice de Información del Ejercicio del Gasto 2017” (en línea), https://imco.org. $\mathrm{mx} /$ temas/indice-de-informacion-del-ejercicio-del-gasto-2017/ (consulta de mayo de 2018).

15 Instituto Mexicano para la Competitividad (IMCO), La caja negra del gasto público, México, Imco, 2010.

${ }^{16}$ El dato corresponde a la provincia de Santa Fe entre 2006 y 2008. Véase Programa de Gasto Público y Rendición de Cuentas, Province of Santa Fe. Republic of Argetina. Public Financial Management Assessment, 2012, https://pefa.org/assessment/ar-santa-fe-province-jul12-pfmpr-sn-public-en (consulta de mayo de 2018). 
Para responder a estas preguntas, los objetivos de la presente investigación son los siguientes: 1) ofrecer información sobre la brecha entre el presupuesto y el ejercicio del gasto estatal durante el periodo 2003-2016, y 2) mediante un análisis para datos de tipo panel, determinar si la alineación partidista vertical entre el gobierno nacional y el de los estados tiene un efecto en ésta.

El presente documento se compone de cuatro secciones. En la primera, se expone el argumento teórico que sirve de sustento para esta investigación, así como los principales resultados de investigaciones previas. En la segunda sección se muestran los datos sobre la brecha entre lo presupuestado y lo ejercido a nivel estatal entre 2003 y 2016. Se trata de información original que hasta ahora no había sido publicada. En la tercera, se hace un análisis de datos de tipo panel y se presentan los resultados. Finalmente, se cierra con una sección de conclusiones y reflexiones.

\section{ALINEACIÓN PARTIDISTA VERTICAL: ARGUMENTOS Y EVIDENCIA}

En esencia, el federalismo puede definirse como un sistema en el que existen, al menos, dos niveles de gobierno establecidos constitucionalmente; ambos gobiernan el mismo territorio y población, y cada uno de éstos tiene la autoridad para tomar algunas decisiones de manera independiente de los otros. ${ }^{17}$ Debido a que México es una república federal, en este trabajo se toma como principal argumento teórico el efecto que puede tener la alineación partidista vertical sobre la relación entre el gobierno federal y los gobiernos estatales.

Una de las primeras ideas al respecto fue elaborada por Riker y Schaps, quienes destacaron que las disputas intergubernamentales son inherentes a un sistema federal que ope-

17 W. Riker, Federalism: Origin, Operation, Significance, Boston, Little, Brown and Co., 1964. 
ra en forma eficaz. ${ }^{18}$ Dado que en este tipo de sistemas hay por lo menos dos niveles de gobierno con autonomía, es posible que surjan diferencias entre ellos en determinados asuntos. En este contexto institucional, el partido político puede ser una fuente de conflicto o de coordinación: si cada nivel de gobierno está en manos de partidos políticos diferentes, y especialmente con ideologías opuestas, entonces hay más posibilidades de que el conflicto surja. En contraste, cuando hay homogeneidad partidista entre los niveles de gobierno, la posibilidad de conflicto entre ellos disminuye. Por lo tanto, el nivel de coordinación o de conflicto es regulado por la unidad o división partidista entre el gobierno federal y los subnacionales. Estas situaciones también se han denominado gobierno unificado y gobierno dividido vertical, respectivamente. ${ }^{19}$

Retomando el argumento anterior, Rodden expone que un problema básico del federalismo es que los incentivos políticos pueden dificultar las negociaciones entre el gobierno nacional y los estados, específicamente en el diseño de las relaciones intergubernamentales. ${ }^{20}$ Aunque las federaciones buscan obtener beneficios colectivos, pueden caer en la trampa de las decisiones conjuntas. Por ejemplo, si un nuevo contrato tiene beneficios para toda la federación (gobierno federal y estados), es posible que algunos estados no cooperen para mantener sus beneficios privados derivados del statu quo. Esto cobra especial importancia cuando las reformas requieren la cooperación de todos los actores.

18 W. Riker y R. Schaps, "Disharmony in Federal Government", Behavioral Science, vol. 2 (1957), pp. 276-289.

${ }^{19} \mathrm{El}$ gobierno unificado vertical existe cuando el gobierno nacional y el subnacional están en manos del mismo partido político; y el gobierno dividido en forma vertical sucede cuando los gobiernan partidos distintos. Aquí se utilizan de manera indistinta los conceptos de alineación partidista vertical y gobierno dividido vertical.

${ }^{20}$ J. Rodden, "Creating a More Perfect Union: Political Parties and the Reform of Federal Systems" (manuscrito), Boston, MIT, Departamento de Ciencia Política, 2001. 
Pero la cooperación de los funcionarios subnacionales puede obtenerse si su futuro político está determinado parcialmente por las cuestiones electorales externas. En otras palabras, si bien las probabilidades de reelección de los políticos se ven afectadas por lo que dicen y hacen, también es relevante el valor de la etiqueta de sus partidos. En un sistema federal, el valor de la etiqueta del partido político está determinado casi completamente por el ámbito nacional.

Cuando un mismo partido político controla ambos niveles de gobierno, los políticos subnacionales no obstaculizarán la política del gobierno federal, porque con ello podrían afectar la imagen de su partido y su propio futuro político. En otras palabras, los funcionarios subnacionales que pertenecen al mismo partido del presidente tienen, al compartir la etiqueta partidista, incentivos para cooperar con él. De lo anterior se deduce que, en contraparte, los estados gobernados por la oposición no cooperarán con el presidente, de tal forma que su imagen se deteriore y se genere un impacto negativo en las elecciones para él y su partido.

Por su parte, Garman, Haggard y Willis se preguntan por los determinantes de las relaciones fiscales intergubernamentales. ${ }^{21}$ En su argumento, establecen que el diseño de la descentralización se deriva de las negociaciones entre los niveles de gobierno. En éstas, cada nivel tiene determinadas preferencias: el gobierno nacional prefiere transferir responsabilidades sin los recursos necesarios para llevarlas a cabo y, en caso de destinar recursos, elige que estén etiquetados; en contraste, los gobiernos subnacionales priorizan obtener transferencias cuya cantidad se determine mediante fórmulas claras y en cuyo destino tengan el poder de decisión.

Retomando las ideas de Riker, estos autores establecen que el tipo de relación entre los niveles de gobierno dependerá de la alineación partidista vertical y de la estructura in-

${ }^{21}$ C. Garman, S. Haggard y E. Willis, "Fiscal Decentralization: A Political Theory with Latin American Cases", World Politics, vol. 53, núm. 2 (2001), pp. 205-236. 
terna del partido político. Las preferencias descritas de cada nivel de gobierno serán más antagónicas en contextos de gobierno dividido vertical, es decir, cuando el presidente y los gobernadores son de partidos diferentes. Aquí, el gobierno central podría transferir algunas funciones a los gobierno subnacionales, pero se negará a dar recursos a sus oponentes. Por su parte, los gobernadores buscarán atar las manos del gobierno central por medio del establecimiento de fórmulas fijas en la distribución de los recursos. En el escenario opuesto, con gobierno unificado vertical, la confrontación será menor.

Rodden y Wibbels también destacan que el funcionamiento del federalismo depende de la dimensión política entre los niveles de gobierno. ${ }^{22}$ Dado que los líderes nacionales tienen incentivos para responder a las preferencias del electorado nacional, se enfocan en el buen desempeño de los bienes públicos nacionales. Para lograr este objetivo, estos líderes necesitan la cooperación de los funcionarios subnacionales, la cual es posible cuando el destino político de éstos lo determinan sus copartidarios a nivel federal. Por ejemplo, si la estabilidad macroeconómica es la clave para el éxito del partido nacional, y si ello tiene efectos positivos en las elecciones subnacionales, entonces los funcionarios del mismo partido del presidente tienen incentivos para cooperar y lograr aquel objetivo. Una actitud opuesta podría ser contraproducente para el futuro político del partido, a nivel tanto nacional como local.

Finalmente, Jones, Sanguinetti y Tommasi recurren a un argumento similar, en el que la dimensión partidista es importante. ${ }^{23}$ Los autores conciben la selección de la política fiscal como un juego de recursos comunes, en donde los ju-

${ }^{22}$ J. Rodden y E. Wibbels, "Beyond the Fiction of Federalism. Macroeconomic Management in Multitiered Systems", World Politics, vol. 54, núm. 4 (2002), pp. 494-531.

${ }^{23}$ M. Jones, P. Sanguinetti y M. Tommasi, "Politics, institutions, and fiscal performance in a federal system: an analysis of the Argentine provinces", Journal of Development Economics, vol. 61, núm. 2 (2000), pp. 305-333. 
gadores (políticos electos) buscan maximizar el bienestar de sus electores con la finalidad de ganar las elecciones. Debido a que el presidente es responsable de la política macroeconómica, tendrá incentivos para mantener una política fiscal conservadora en comparación con los gobernadores. En un contexto de gobierno unificado vertical y alta disciplina partidista, el presidente cuenta con recursos adicionales, derivados de su cargo como presidente del partido nacional, para obtener la cooperación de los gobernadores. En contraste, en un gobierno dividido vertical, el presidente enfrentará más dificultades para lograr el apoyo de la oposición.

¿Hay diferencias entre los gobiernos divididos y los unificados verticalmente? La información internacional sobre la alineación partidista vertical indica que esta variable tiene un efecto sobre diversos aspectos. Por ejemplo, se ha demostrado que cuando existe alineación partidista vertical o gobierno unificado vertical, los niveles de gasto de los estados son menores, ${ }^{24}$ hay mayor centralización fiscal, ${ }^{25}$ el superávit es más alto y la inflación más baja, ${ }^{26}$ los acuerdos se llevan de mejor manera, ${ }^{27}$ son menores las disputas entre los niveles de gobierno ${ }^{28}$ y el gobierno federal delega responsabilidades a los estados. ${ }^{29}$

En el caso mexicano los resultados son contrastantes. Entre los trabajos que sí encontraron un efecto, mencionamos los siguientes. Flamand demostró que, entre 1995 y 1999, los

${ }^{24}$ M. Jones, P. Sanguinetti y M. Tommasi, art.cit.

${ }^{25}$ C. Garman, S. Haggard y E. Willis, art. cit.

${ }^{26}$ J. Rodden y E. Wibbels, art. cit.

27 A. Lennox, "A Little Help from My Friends: The Partisan Factor and Intergovernmental Negotiations in Canada”, Publius: The Journal of Federalism, vol. 43, núm. 4 (2012), pp. 701-727.

28 J. Bulman-Pozen, "Partisan Federalism", Harvard Law Review, vol. 127, núm. 4 (2014), pp. 1077-1146; J. Read, "Constitutionalizing the Dispute: Federalismin Hyper-Partisan Times", Publius: The Journal of Federalism, vol. 46, núm. 3 (2016), pp. 337-365.

${ }^{29}$ G. Krause y A. Bowman, "Adverse Selection, Political Parties, and Policy Delegation in the American Federal System”, The Journal of Law, Economics, Ė Organization, vol. 21, núm. 2 (2005), pp. 359-387. 
estados gobernados por el mismo partido del presidente recibieron menos transferencias federales que aquellos estados en manos de la oposición. ${ }^{30}$

También se ha demostrado que, entre 2009 y 2017, hubo un sesgo partidista en la distribución de los recursos del Ramo 23. ${ }^{31}$ Por ejemplo, se observó que durante el gobierno federal priista se dieron más transferencias a los estados gobernados por la oposición. No obstante, en años previos a la elección presidencial los gobiernos del mismo partido del presidente recibieron más recursos.

Con datos a nivel municipal en el periodo 2005-2015, Benton comprobó que cuando hay alineación partidista entre el municipio, el estado y el gobierno federal, los municipios adquieren menos deuda pública que aquéllos en los que sólo hay alineación entre el municipio y el estado. ${ }^{32}$ Para Benton, esto indica que el liderazgo partidista influye en la conducta de los municipios más que la reputación del partido.

Incluso en el tema de la violencia, con datos de 2006 a 2012, se comprobó que la violencia criminal en los municipios fue mayor cuando el municipio y el estado estuvieron gobernados por partidos diferentes al Partido Acción Nacional (PAN) y mucho mayor en los estados gobernados por el Partido de la Revolución Democrática (PRD). ${ }^{33}$

En contraste, otras investigaciones no han hallado efectos de la alineación partidista vertical. Por ejemplo, con datos de 1993 a 2002, Velázquez no encontró diferencias con respecto

${ }^{30}$ L. Flamand, "El juego de la distribución de recursos en un sistema federal. La influencia del gobierno dividido verticalmente en la asignación de fondos federales a los estados mexicanos", Política y gobierno, vol. 13, núm. 2, (2006), pp. 315-359.

31 México Evalúa, Arquitectura del Ramo 23, México, México Evalúa, 2018.

${ }^{32}$ A. Benton, "Party Leader or Party Reputation Concerns? How Vertical Partisan Alignment Reins in Subnational Fiscal Profligacy", The Journal of Politics, vol. 81, núm. 1 (2019), pp. 201-214.

${ }^{33}$ G. Trejo y S. Ley, "Federalismo, drogas y violencia. Por qué el conflicto partidista intergubernamental estimuló la violencia del narcotráfico en México”, Política y Gobierno, vol. 23, núm. 1 (2016), pp. 11-56. 
al gasto de los estados. ${ }^{34}$ Ibarra, con datos de 1998 a 2006, tampoco halló un efecto en el tema de la dependencia financiera. ${ }^{35}$ Finalmente, Busmail y Miño analizaron el periodo 2006-2012, y mostraron que la alineación partidista vertical no tuvo un impacto sobre los recursos discrecionales que recibieron los estados del gobierno federal. ${ }^{36}$

A pesar de que estas investigaciones muestran diferentes resultados sobre los efectos de la alineación partidista vertical sobre el gasto público, hasta ahora no se ha puesto atención en la diferencia entre el monto presupuestado y el ejercido. Como se verá en la siguiente sección, los datos muestran que los gobiernos estatales ejercen más recursos de los previamente presupuestados, es decir, hay una brecha entre ambas etapas.

Ya que la economía nacional puede verse afectada por el manejo del gasto público por los gobiernos estatales, el gobierno federal busca que los estados no gasten más de lo que presupuestan, de lo contrario, podría generarse un impacto negativo en la economía y en el partido. La capacidad para lograr aquel objetivo dependerá de la alineación partidista vertical: los estados gobernados por su partido registrarán las menores diferencias entre lo presupuestado y lo ejercido; en contraparte, los estados gobernados por la oposición, al no estar sometidos al control político del presidente, presentarán las mayores diferencias. En concreto, la hipótesis es la siguiente: $H 1$, en contextos de gobierno dividido vertical, la brecha entre lo presupuestado y lo ejercido será mayor que en contextos de gobierno unificado vertical.

Esta hipótesis se basa en la siguiente condición: existe un nivel suficiente de disciplina partidista, de tal forma que lo dictado por el presidente tiene una alta probabilidad de ser

${ }^{34}$ Velázquez, art. cit.

35 Ibarra, art. cit.

36 A. Busmail y J. Miño, "Estrategias partidistas y cooperación entre niveles de gobierno durante la presidencia de Felipe Calderón", en N. Loza e I. Méndez (coords.), Poderes y democracias. La política subnacional en México, Ciudad de México, Flacso-IEdf, 2016, pp. 113-130. 
acatado por los funcionarios subnacionales de su mismo partido. Cabe decir que esta condición se ha comprobado a nivel estatal en otros estudios relativamente recientes. ${ }^{37}$

Por supuesto, hay otros argumentos que compiten con el nuestro. Aquí se consideran dos: la teoría partidista y los ciclos electorales. La primera teoría, denominada partidista, establece que la ideología de los partidos políticos influye en el contenido y las características de las políticas que implementan una que vez están en el gobierno. ${ }^{38}$ La división entre una ideología de izquierda y una de derecha se basa en la postura que toman los partidos en cuestiones políticas relevantes, como son los aspectos económicos y sociales. ${ }^{39} \mathrm{Al}$ respecto, Hibbs señala que los gobiernos de izquierda tienen preferencia por el pleno empleo, la distribución equitativa del ingreso y la expansión económica. Por su parte, los gobiernos de derecha prefieren la estabilidad de precios y el equilibrio presupuestal. ${ }^{40}$

La evidencia internacional al respecto muestra diversos resultados: si hay efectos, éstos son débiles o dependen de otras condiciones. ${ }^{41}$ En México, los estudios subnacionales

37 F. Sleman, El poder presupuestal de los gobernadores en México (20002012): la influencia de las reglas presupuestales y del pluralismo legislativo [tesis de doctorado], México, Flacso, 2014; P. Gutiérrez, El poder de los gobernadores en México 2001-2012: límites institucionales y políticos a nivel subnacional [tesis de doctorado], México, Flacso, 2013.

38 S. Hartmann, Partisan Policy-Making in Western Europe. How Ideology Influences the Content of Government Policies, Mannheim, Springer, 2015.

${ }^{39}$ Loc. cit.

${ }^{40}$ D. Hibbs, "Political Parties and Macroeconomic Policy", The American Political Science Review, vol. 71, núm. 4 (1977), pp. 1467-1487.

41 Son abundantes las investigaciones al respecto; aquí mencionamos sólo algunas. H. Herwartz y B. Theilen, "Partisan influence on social spending under market integration, fiscal pressure and institutional change", European Journal of Political Economy, vol. 34 (2014), pp. 409-424; H. Kwon y J. Pontusson, "Globalization, labour power and partisan politics revisited", Socio-Economic Review, vol. 8, núm. 2 (2010), pp. 251-281; M. Loftis y P. Mortensen, "A new approach to the study of partisan effects on social policy", Journal of European Public Policy, vol. 24, núm. 6 (2017), pp. 890-911; N. Potrafke, "Does government ideology influence budget composition? Em- 
tampoco han llegado a un consenso. Por ejemplo, Montemayor no encontró diferencias en los niveles de deuda pública entre los gobiernos priistas y los de la oposición. ${ }^{42}$ Velázquez halló que los gobiernos panistas gastan menos que los priistas, mientras que los perredistas gastan más que los priistas. ${ }^{43}$ Por su parte, Ibarra comprobó que el efecto sólo es parcial en el tema de la dependencia financiera. ${ }^{44}$ Finalmente, la investigación de Benton y Smith, enfocada en los gobiernos municipales, demostró el efecto de la ideología: la deuda de los gobiernos panistas fue menor a la de los gobiernos priistas. ${ }^{45}$

En relación con la teoría oportunista o electoral (también llamada de los ciclos electorales), el argumento consiste en que los funcionarios manipulan la política económica para aumentar sus probabilidades de reelección, independientemente de la ideología de los partidos en el gobierno. ${ }^{46}$ Generalmente, se ha establecido que a medida que se acerca el año electoral, los funcionarios modificarán ciertas varia-

pirical evidence from OECD countries", Economics of Governance, vol. 12, núm. 2 (2011), pp. 101-134; N. Potrafke, "The growth of public health expenditures in OECD countries: Do government ideology and electoral motives matter?", Journal of Health Economics, vol. 29, núm. 6 (2010), pp. 797-810; L. Sáez y A. Sinha, "Political Cycles, Political Institutions and Public Expenditures in India, 1980-2000", British Journal of Political Science, vol. 40, núm. 1 (2009), pp. 91-113; S. Sakurai y N. Menezes, "Opportunistic and partisan election cycles in Brazil: new evidence at the municipal level”, Public Choice, vol. 148, núms. 1-2 (2010), pp. 233-247; C. Schmitt, "Panel data analysis and partisan variables: how periodization influence partisan effects", Journal of European Public Policy, vol. 23, núm. 10 (2016), pp. 1442-1459.

42 O. Montemayor, art. cit.

${ }^{43}$ C. Velázquez, art. cit.

${ }^{44} \mathrm{~J}$. Ibarra, art. cit.

45 A. Benton y H. Smith, "A Rational Partisan Explanation for Irrational (Sub) Sovereign Debt Behavior: Evidence from Municipal Mexico”, Documentos de Trabajo, núm. 264, cIDE, 2014.

46 W. Nordhaus, "The Political Business Cycle", The Review of Economic Studies, vol. 42, núm. 2 (1975), pp. 169-190; H. Herwartz y B. Theilen, art. cit. 
bles económicas (inflación, empleo, superávit, etcétera) para poder permanecer en el cargo. ${ }^{47}$

Varias investigaciones internacionales revelan que los ciclos electorales sí tienen un efecto sobre el gasto público, sus componentes y otras variables macroeconómicas. ${ }^{48}$ En México, Ramírez y Erquizio demostraron que el efecto del ciclo electoral depende del tema de gasto analizado: por ejemplo, en los años de elecciones para gobernador hubo un efecto sobre el gasto total, pero no en el gasto administrativo ni en obra pública. ${ }^{49}$ Un resultado similar es el de Gámez e Ibarra-Yúnez, quienes hallaron que en los años electorales para gobernador hay un mayor gasto total pero sin efecto sobre el gasto en obras públicas. ${ }^{50}$ Finalmente, Argáez también mostró que el gasto es mayor en los años con elecciones para gobernador, aunque es menor cuando las elecciones para diputados son competitivas. ${ }^{51}$

${ }^{47}$ Existen diferentes versiones y debates dentro de esta teoría, véase $\mathrm{R}$. Franzese, "Electoral and Partisan Cycles in Economic Policies and Outcomes", Annual Review of Political Science, vol. 5 (2002), pp. 369-421.

48 V. Bove, G. Efthyvoulou y A. Navas, "Political cycles in public expenditure: butter vs. guns", Journal of Comparative Economics, vol. 45, núm. 3 (2017), pp. 582-604; H. Dalen y O. Swank, "Government spending cycles: Ideological or opportunistic?”, Public Choice, vol. 89, núms. 1-2 (1996), pp. 193-200; M. Katsimi y V. Sarantides, "Do elections affect the composition of fiscal policy in developed, established democracies?", $P u$ blic Choice, vol. 151, núm. 1 (2012), pp. 325-362; S. Sakurai y N. Menezes, art. cit.; M. Shi y J. Svensson, "Political Budget cycles: Do they differ across countries and why?", Journal of Public Economics, vol. 90, núms. 8-9 (2006), pp. 1367-1389; C. Vergne, "Democracy, elections and allocation of public expenditures in development countries", European Journal of Political Economy, vol. 25, núm. 1 (2009), pp. 63-77.

${ }^{49}$ R. Ramírez y A. Erquizio, art. cit.

${ }^{50}$ C. Gámez y A. Ibarra-Yúnez, "El ciclo político oportunista y el gasto de los estados mexicanos”, Gestión y Política Pública, vol. 18, núm. 1, 2009, pp. 39-65.

51 J. Argáez, "El papel moderador de los congresos locales sobre el ciclo político presupuestal oportunista en los estados mexicanos", Gestión y Política Pública, vol. 25, núm. 2, 2016, pp. 525-549. 
De estos argumentos rivales se derivan las siguientes hipótesis: $H 2$, los gobiernos priistas y perredistas mostrarán una mayor diferencia entre lo presupuestado y lo ejercido en comparación con los gobiernos panistas; y H3, en los años preelectorales y electorales (periodo electoral) habrá una mayor diferencia que en el resto de los años.

La hipótesis $H 2$ implica ubicar al PAN como partido de derecha y al PRD como de izquierda. Aunque el Partido Revolucionario Institucional (PRI) ha sido considerado en el centro del espectro ideológico por otros estudios, ${ }^{52}$ aquí se establece que se aproxima más a la izquierda que al centro en materia del gasto público. En consecuencia, se espera que con gobiernos panistas, la brecha entre lo presupuestado y lo ejercido sea menor, mientras que con gobiernos priistas y perredistas será mayor. En relación con los gobiernos de alianza PAN-PRD, se espera que la diferencia sea mayor a la de los gobiernos panistas.

En el caso de la hipótesis $H 3$, como se indicó, el argumento señala que los políticos pueden manipular el gasto público para incrementar sus posibilidades de reelección en la siguiente contienda electoral. Aquí se considera que en los años preelectoral y electoral, respectivamente, la diferencia entre el presupuesto y lo ejercido será mayor que en el resto de los años.

Si bien los gobiernos estatales podrían establecer una mayor o menor cantidad de gasto desde el propio presupuesto en función de la alineación partidista, de la dimensión ideológica o del calendario electoral, los datos muestran, como se verá en la siguiente sección, que pocas veces se aplica tal cual el gasto presupuestado. La regla es ejercer más recursos: un gobierno estatal puede presupuestar 100000 pesos para un año determinado, pero en la práctica puede ejercer en promedio hasta $38 \%$ más (ver el dato para Tlaxcala). En otras palabras, el presupuesto en sí mismo es un instrumento poco confiable para conocer las preferencias de

${ }^{52}$ G. Trejo y S. Ley, art. cit. 
gasto del gobierno. Por esta razón, Núñez recomienda que es preciso poner más atención a lo que efectivamente se ejerce y no tanto en el presupuesto, ya que éste rara vez se corresponde con la realidad. ${ }^{53}$ En concreto, hay que enfocarse en la distancia entre el plan y la práctica. En la siguiente sección se ofrece información sobre esta diferencia.

\section{GASTO PRESUPUESTADO Y EJERCIDO: LAS BRECHAS}

A NIVEL SUBNACIONAL, 2003-2016

De manera general, el proceso presupuestario se compone de cuatro fases: elaboración, aprobación, ejecución y control. ${ }^{54}$ A nivel estatal, en lo esencial, las constituciones facultan a los gobernadores para diseñar y presentar el proyecto de presupuesto de egresos al Congreso, el cual lo analiza, modifica y aprueba. Una vez aprobado, se devuelve al Ejecutivo para, si no hay observaciones, se publique. Durante el año fiscal, el Ejecutivo se encarga de ejercer el gasto. Finalmente, las entidades de fiscalización superior locales verifican que los recursos se hayan erogado con apego a las leyes respectivas.

Esta investigación se concentra en lo que sucede entre las fases de la aprobación y la ejecución, en concreto, se enfoca en la diferencia que se presenta entre el monto presupuestado y el monto que efectivamente se ejerce al final del año fiscal. Para medir la magnitud de esta diferencia, se considera el porcentaje que ésta representa con respecto al presupuesto de egresos aprobado. A esta variable la denominamos gasto neto ejercido (GNE), ${ }^{55}$ cuya fórmula es la siguiente:

53 L. Núñez, op. cit.

${ }^{54}$ B. Nacif, Para entender el Poder Legislativo de los Estados Unidos Mexicanos, México, Nostra, 2005.

${ }^{55}$ Un indicador similar es utilizado por PEFA y, como se indicó, por la onu en los Objetivos de Desarrollo Sostenible. 


$$
G N E=\frac{(G E-G P)}{G P} * 100
$$

En donde GE es el gasto ejercido y GP, el gasto presupuestado. Como se observa, de la diferencia entre ambos valores se obtiene su porcentaje con respecto a los recursos presupuestados. Un valor positivo indica que existe un sobreejercicio y un valor negativo indica un subejercicio. Los datos del GP se obtuvieron de los presupuestos de egresos de cada estado mediante solicitudes de información. ${ }^{56}$ Los datos del GE se obtienen de la cuenta pública, sin embargo, debido a la poca disponibilidad de información, se recurrió a la base Finanzas públicas de estados y municipios, del Instituto Nacional de Estadística y Geografía (INEGI). Los datos para los 31 estados durante el periodo 2003-2016 arrojan un total de 434 observaciones, de las cuales se obtuvo información para 423 (97\%).

Antes de empezar con la descripción de los datos del GNE, vale la pena detenerse en el comportamiento del gasto presupuestado y ejercido, el cual se expone en la gráfica 1. En primer lugar, se observa que el gasto ejercido es mayor al presupuestado. Para el periodo 2003-2016, el promedio del gasto presupuestado fue de 35847 millones de pesos y el del gasto ejercido fue de 41328 millones de pesos (a precios de 2013). En segundo lugar, se aprecia que el gasto, tanto presupuestado como ejercido, aumentó de manera clara: en 2003, el primero fue de 26814 millones y el segundo de 29429 millones de pesos, pero en 2016 llegó a 44533 millones y 50955 millones de pesos, respectivamente.

De acuerdo con el PEFA, que es un marco de referencia internacional para la evaluación y presentación de informes sobre fortalezas y debilidades de la gestión de las finanzas públicas, un ejercicio del gasto entre +-11 y $+-15 \%$ respecto al gasto programado se considera como un nivel básico de de-

56 Se consultaron los periódicos oficiales y se hicieron solicitudes de acceso a la información a los congresos estatales y a las secretarías de finanzas de los estados. 
sempeño de acuerdo con las buenas prácticas internacionales. Pero se considera que un gasto que excede el $+-15 \%$ se aleja de las buenas prácticas. ¿Qué magnitudes presentan los gobiernos estatales en México? Cuando se analizan los valores del GNE, se observa que, para el periodo 2003-2016, el promedio fue de $18.6 \%$, cifra mayor al promedio de $7 \%$ del gobierno federal reportado por Núñez y al umbral del PEFA de $15 \% .{ }^{57}$ Este primer dato muestra que los gobiernos estatales están ejerciendo más recursos de los que aprueban sus respectivos congresos y que tal magnitud los aleja de las buenas prácticas internacionales.

\section{GRÁFICA 1}

Gasto estatal presupuestado y ejercido promedio anual, 2003-2016

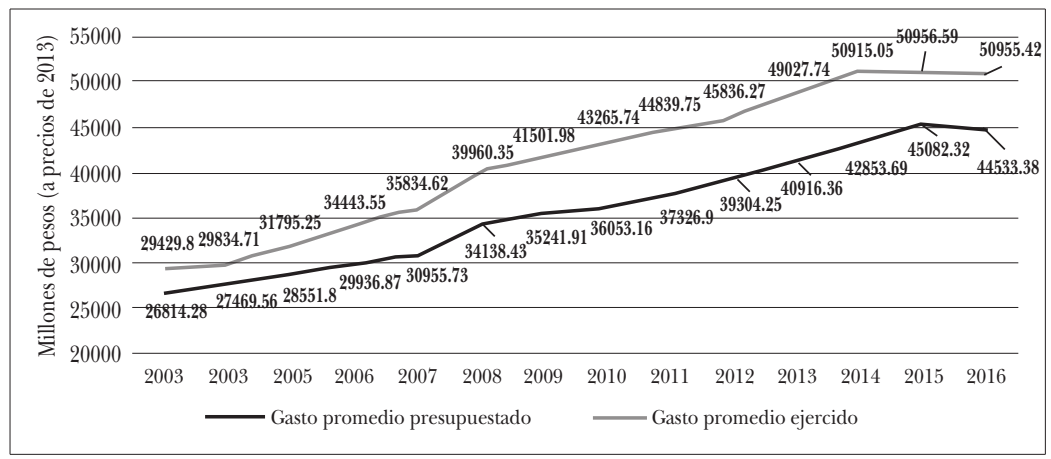

Fuente: elaboración propia con datos del INEGI y los presupuestos de egresos de cada estado.

En la gráfica 2, se presentan los valores promedio anuales del GNe. Destaca que en todos los años hay valores positivos, es decir, el sobreejercicio del gasto es una práctica recurrente entre los estados. También se aprecia que entre 2004 y 2008 hubo un aumento considerable, pasando de 12.9 a $22.3 \%$,

${ }^{57}$ L. Nuñez, op. cit. 
respectivamente. En 2012 bajó de manera importante a 17.7\%, y cerró en 2016 con $15.9 \%$. En general, se observa que en 12 de los 14 años el GNe superó el 15\%. Para comparar, se muestra el monto en pesos de la diferencia entre el presupuesto programado y el ejercido. Con ambos indicadores se detecta que no sólo hay un sobreejercicio constante del gasto público, sino también un aumento en la mayor parte del periodo, especialmente entre 2004 y 2011.

GRÁFICA 2

Porcentaje promedio anual del GNE, 2003-2016

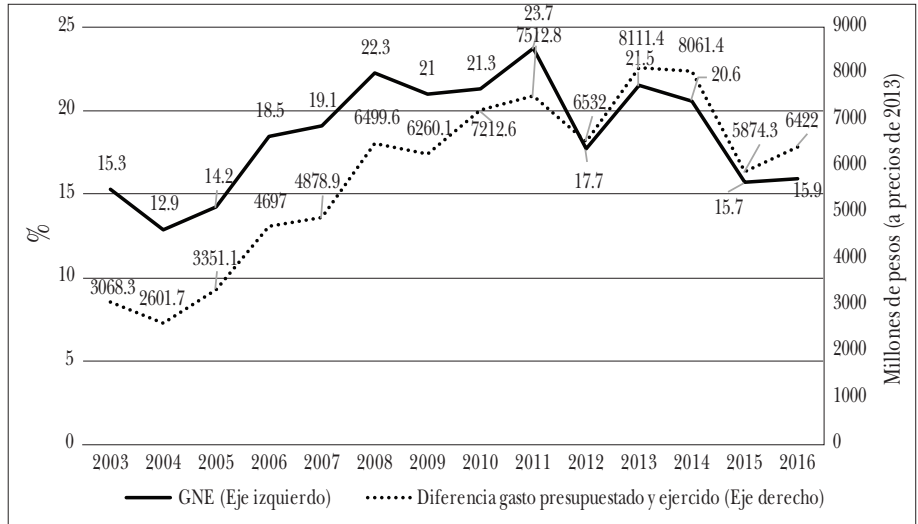

Fuente: elaboración propia con datos del INEGI y los presupuestos de egresos de cada estado.

¿Qué se puede observar cuando se compara el GNE entre los estados? En la gráfica 3 se identifican diferencias importantes. Por un lado, se ubican los estados con los máximos valores: Tlaxcala, Hidalgo y Colima, con 38.7, 29.8 y 29\%, respectivamente. En el lado opuesto, están Baja California, Jalisco y Yucatán, con 7.4, 7.9 y 8.1\%, respectivamente. En términos comparados, todos superan el sobreejercicio promedio del gobierno federal de $7 \%$ y 19 estados exceden el umbral de $15 \%$ del PEFA. 
GRÁFICA 3

Porcentaje promedio del GNE por estado, 2003-2016

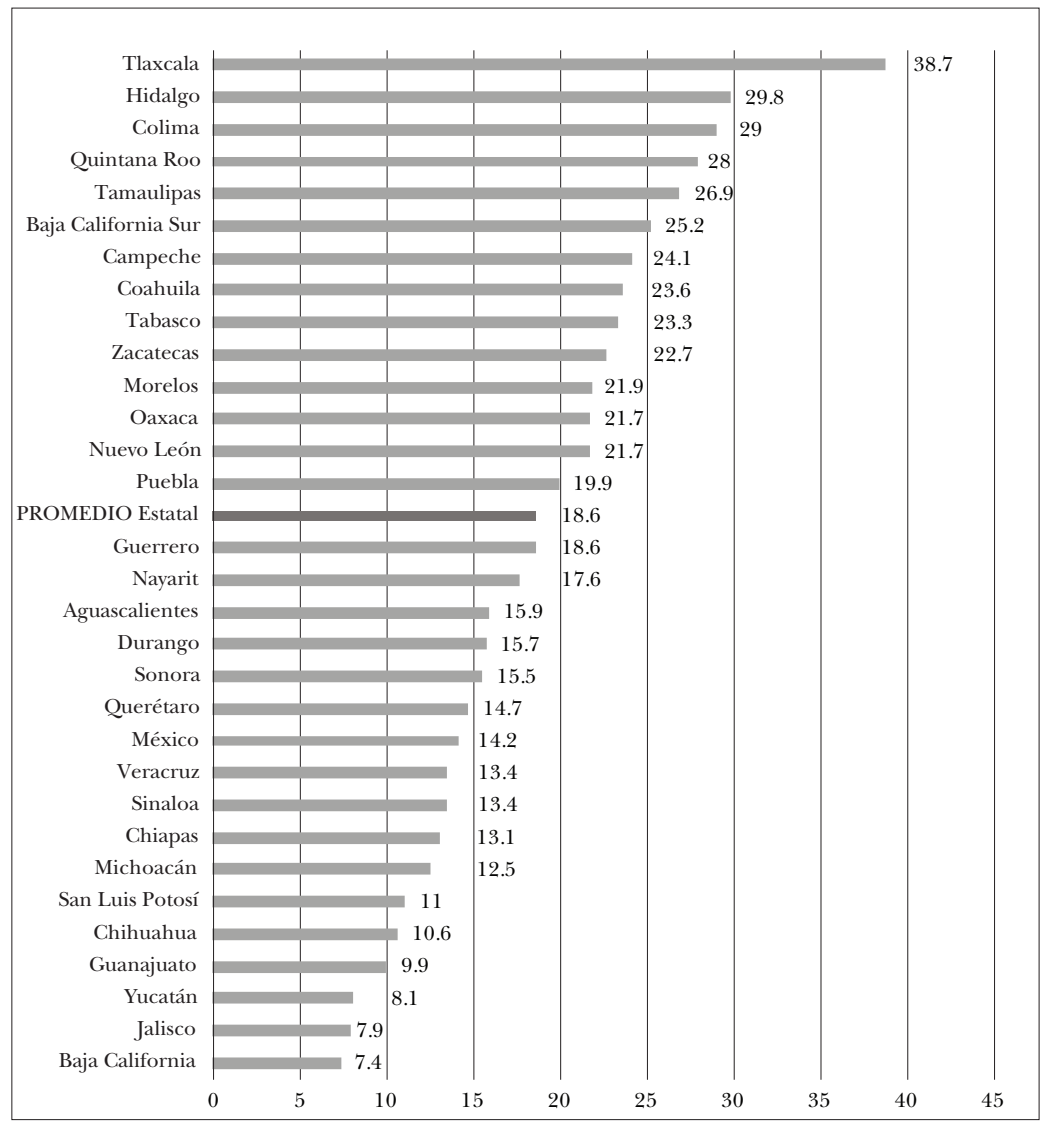

Fuente: elaboración propia con datos del INEGI y los presupuestos de egresos de cada estado.

A lo largo del tiempo, cada estado presenta variaciones en los niveles del GNE. En la gráfica 4 se observa nuevamente que el sobreejercicio es una práctica común, pero aquí se pueden detectar algunos años en los que se presentaron subejercicios: Chihuahua en 2016 (-4.6\%); Guanajuato en 2003 (-2.3\%); Estado de México, 2003 (-1.5\%) y 2004 (-6.7\%); 
Querétaro, $2004(-6.0 \%)$ y 2005 (-1.5\%); Quintana Roo, 2015 (-20.9\%); San Luis Potosí, 2009 (-0.3\%); Sonora, 2008 (-14.1\%); Veracruz, $2016(-1.15 \%)$; y Yucatán en $2011(-5.0 \%)$, $2012(-6.2 \%), 2014(-5.1 \%), 2015(-3.5 \%)$ y $2016(-3.5 \%)$.

Además, hay diversas tendencias. Por un lado, están los casos con poca variación en su GNe, como Jalisco, Oaxaca, Chihuahua, San Luis Potosí, Chiapas, Baja California, Baja California Sur, Durango y Puebla. Por el otro lado, están aquéllos con oscilaciones considerables. Por ejemplo, en Coahuila, entre 2004 y 2007, los niveles de GNE no habían rebasado 15\%, pero a partir de 2008 comenzaron a aumentar: $30.7 \%$ en 2009; 64\% en 2010; y 108.4\% en 2011; después, desde 2012 se redujeron y no superaron el 11\%. Otro caso es Quintana Roo, que registró $15.5 \%$ en 2003 y posteriormente incrementó sus niveles: $24.3 \%$ en $2006 ; 48.9 \%$ en 2008; llegó al máximo con $92.3 \%$ en 2011 y en los años siguientes tuvo niveles entre -20.9 y $30.7 \%$. En Nuevo León también los menores niveles se presentaron al inicio del periodo y después comenzaron a aumentar: $11.1 \%$ en $2003 ; 22.7 \%$ en $2008 ; 73.4 \%$ en 2013 y en los siguientes años presentó magnitudes entre 14.8 y $23 \%$. Por último, en Tabasco se observó una tendencia interesante, ya que al inicio del periodo mostró porcentajes elevados y después los redujo de manera constante: su GNE fue de $71.9 \%$ en 2003; $40.3 \%$ en 2006; 20.4\% en 2009 y desde 2012 las cifras fueron menores a $10 \%$.

En suma, a partir de los datos anteriores, pueden destacarse los siguientes aspectos. En primer lugar, existe una diferencia considerable entre el presupuesto y el monto ejercido. Como se indicó, en promedio, el GNE fue de $18.6 \%$, cifra que es mayor a la reportada a nivel federal y cuya medida aleja a los gobiernos estatales de las buenas prácticas internacionales. Lo anterior indica que los presupuestos estatales son poco realistas y que lo planeado no se corresponde con la práctica. En segundo lugar, durante el periodo, la magnitud del gasto ha estado aumentando en lo que toca tanto al GNE como en términos brutos. Aunque en algunos años se redujo, su tamaño sigue siendo considerable. En tercer lugar, si bien todos los estados 
presentan sobreejercicios, es preciso destacar que hay diferencias importantes tanto transversal como longitudinalmente.

Gráfica 4

Porcentaje anual del GNE por estado, 2003-2016

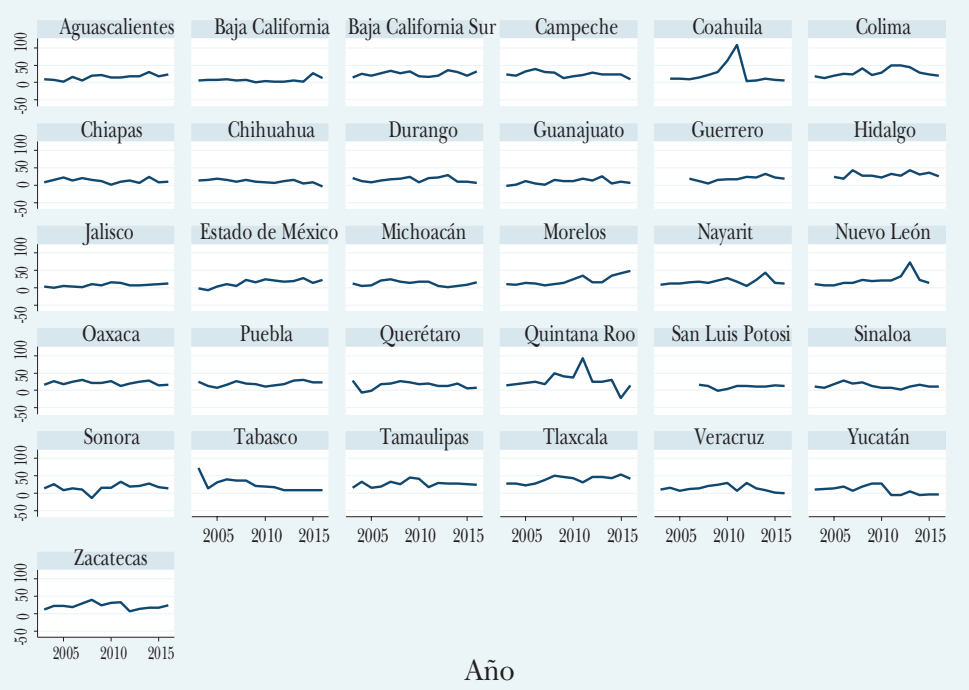

Fuente: elaboración propia con datos del INEGI y los presupuestos de egresos de cada estado.

\section{MÉTOdo y RESUltados}

En esta sección se pone a prueba el argumento expuesto en la primera parte del texto. Para ello, se utiliza una base de datos de tipo panel, que incluye 14 años y 31 estados, lo que resulta en 434 observaciones. Como se indicó, pudo obtenerse información para 423 observaciones del GNE, sin embargo, se eliminó una correspondiente al primer año de gobierno de Jaime Rodríguez Calderón (2016), gobernador de Nuevo León, ya que fue un candidato independiente o de libre postulación partidista.

En el cuadro 1 se muestra la estadística descriptiva de las variables que se utilizarán. Se añadió el GNE per cápita, el 
Cuadro 1

Estadística descriptiva

\begin{tabular}{|c|c|c|c|c|c|}
\hline Variable & Media & $\begin{array}{l}\text { Desviación } \\
\text { estándar }\end{array}$ & Mínimo & Máximo & Observaciones \\
\hline GNE & 18.6 & 13.3 & -20.9 & 108.4 & 422 \\
\hline GNE per cápita ${ }^{\mathrm{a}}$ & 2076.7 & 1587.8 & -4862.7 & 12615.3 & 422 \\
\hline Partido en el gobierno & & & & & 433 \\
\hline PAN & & & & & $\begin{array}{c}86 \\
(20 \%)\end{array}$ \\
\hline PRI $I^{\mathrm{b}}$ & & & & & $\begin{array}{c}261 \\
(60 \%)\end{array}$ \\
\hline PRD & & & & & $\begin{array}{c}53 \\
(12 \%)\end{array}$ \\
\hline$P A N / P R D$ & & & & & $\begin{array}{c}33 \\
(8 \%)\end{array}$ \\
\hline Alineación partidista vertical & & & & & 433 \\
\hline Gobierno dividido vertical & & & & & $\begin{array}{c}258 \\
(60 \%)\end{array}$ \\
\hline Gobierno unificado vertical ${ }^{\mathrm{C}}$ & & & & & $\begin{array}{c}175 \\
(40 \%)\end{array}$ \\
\hline Años & & & & & 433 \\
\hline Año preelectoral + año electoral ${ }^{\mathrm{d}}$ & & & & & $\begin{array}{c}163 \\
(38 \%)\end{array}$ \\
\hline Años restantes (no electorales) & & & & & $\begin{array}{c}270 \\
(62 \%)\end{array}$ \\
\hline $\begin{array}{l}\text { Porcentaje de la deuda contratada en el } \\
\text { año t con respecto a los ingresos estatales }\end{array}$ & 3.7 & 5.8 & 0 & 52.4 & 433 \\
\hline Población (millones de personas) ${ }^{\mathrm{e}}$ & 3.4 & 2.9 & 0.5 & 16.7 & 433 \\
\hline PIB estatal (miles de millones de pesos) ${ }^{\mathrm{f}}$ & 390.1 & 293.1 & 67.7 & 1480.9 & 433 \\
\hline
\end{tabular}

Fuente: elaboración propia con datos del INEGI, de los presupuestos de egresos de cada estado, de los organismos públicos locales electorales y de las solicitudes de acceso a la información a los congresos estatales.

a Pesos a precios de 2013.

b Ya que el PVEm gobierna un solo estado y ganó en alianza con el PRI (en Chiapas), se contabilizó en el grupo de este partido.

${ }^{c}$ Los gobiernos del PAN-PRD se consideraron como GUV durante la administración federal panista.

d Sólo considera elecciones para gobernador.

e CONAPO, Estimaciones y proyecciones de la población por entidad federativa.

${ }^{\mathrm{f}}$ INEGI, precios de 2013. 
cual indica que hay un sobreejercicio promedio de 2076 pesos por habitante. También se observa que $20 \%$ de los estados fueron gobernados por el PAN , $60 \%$ por el PRI, $10 \%$ por el PRD y $8 \%$ por una alianza electoral PAN-PRD. En relación con la alineación partidista vertical, en $65 \%$ de las observaciones hubo un gobierno dividido vertical, y en el $35 \%$ restante, un gobierno unificado vertical. Los años preelectorales y electorales representan el 37\% del total. Finalmente, las variables de control son la deuda pública contratada en el año como porcentaje de los ingresos totales, así como la población y el producto interno bruto (PIB) estatal. En el caso de la deuda contratada, se eligió esta variable porque para realizar un sobreejercicio se requieren recursos adicionales, y una fuente para allegarse de éstos es la deuda pública. Por lo tanto, se espera que exista una relación positiva entre la deuda contratada y el GNE. En el caso de la población y el PIB, se trata de variables de control estándar.

Se determinó utilizar efectos fijos, ya que permite controlar por la heterogeneidad no observada y estudiar las causas del cambio dentro de las unidades. Ya que se detectaron problemas de heteroscedasticidad, se recurrió a estimadores con errores estándar corregidos para panel (panel corrected standard errors o PCSE). El modelo es:

$$
\begin{aligned}
G N E_{i, t}= & \beta_{1} g d v_{i, t}+\beta_{2} p g_{i, t}+\beta_{3} \text { pelec }_{i, t}+\beta_{4} \text { deuda }_{i, t}+ \\
& \beta_{5} \text { lpob }_{i, t}+\beta_{6} \text { lpib }_{i, t}+E_{i}+T_{t}+\varepsilon_{i, t}
\end{aligned}
$$

En donde GNE es el gasto neto ejercido, expresado en porcentaje; $g d v$ es una variable dicotómica para la alineación partidista vertical (gobierno dividido vertical=1; gobierno unificado vertical $=0$ ); $p g$ es la variable categórica para el partido político en el gobierno (PAN: pg1=0, pg2=0, pg3=0; PRI: pg1=1, pg2=0, pg3=0; PRD: pg1=0, pg2=1, pg3=0; PAN-PRD: pg1=0, pg2=0, pg3=1); pelec es una variable categórica sobre el periodo electoral (años preelectorales y electorales=1; el resto de los años=0); deuda se refiere al porcentaje que representa la deu- 
da contratada en el año $t$ con respecto a los ingresos totales; lpob es el logaritmo natural de la variable población; lpib es el logaritmo natural del producto interno bruto estatal; y también se controla por el efecto de los estados $(E)$ y por los efectos temporales $(T)$. Se complementa el análisis utilizando el GNE per cápita (modelo M2). Los resultados se muestran en el cuadro 2.

\begin{tabular}{lcc} 
& CUADRO 2 & \\
& Resultados & \\
& $M 1$ & M2 \\
& $($ GNE) & (GNE pesos per cápita) \\
\hline Gobierno dividido vertical & $2.783^{* *}$ & $275.2^{* * *}$ \\
& $(1.248)$ & $(141.7)$ \\
\hline Gobierno PRI & $4.015^{* *}$ & 343.2 \\
& $(1.960)$ & $(219.5)$ \\
\hline Gobierno PRD & 1.880 & -8.2 \\
& $(2.699)$ & $(289.2)$ \\
\hline Gobierno PAN-PRD & $7.732 * * *$ & $802.4 * * *$ \\
& $(2.594)$ & $(277.7)$ \\
\hline Periodo electoral & 0.287 & 22.2 \\
& $(1.045)$ & $(116.9)$ \\
\hline Deuda pública & $1.022 * * *$ & $129.8 * * *$ \\
& $(0.117)$ & $(14.3)$ \\
\hline Población (logaritmo natural) & -1.254 & \\
& $(24.769)$ & 208.8 \\
\hline PIB estatal (logaritmo natural) & 1.979 & $(851.7)$ \\
& $(6.894)$ & 0.5771 \\
\hline$R^{2}$ & 0.5256 & 422 \\
\hline Observaciones & 422 & \\
\hline$*$ p $<=0.1$ & & \\
$* *$ p $<=0.05$ & & \\
$* * * p<=0.01$ & & \\
\hline
\end{tabular}

Fuente: elaboración propia. 
En primer lugar, sí se observa un efecto por la alineación partidista vertical. Específicamente, cuando los estados son gobernados por la oposición hay una mayor brecha entre lo presupuestado y lo ejercido. En promedio, en contextos de gobierno dividido vertical, los estados sobreejercieron 275.2 pesos más que en el escenario opuesto. De acuerdo con el argumento, los estados gobernados por la oposición no tienen incentivo u obligación de cooperar con el presidente, por lo tanto, sus decisiones de gasto tienen más libertad de maniobra. En otras palabras, si el objetivo del presidente es mantener un equilibrio fiscal, se observa que sólo los estados gobernados por su partido cooperan para lograrlo. Esto se reflejó en la menor magnitud que registró el GNE en tales estados. Lo anterior permite comprobar la H1.

En el caso de la ideología del partido en el gobierno estatal, se observa que con gobiernos priistas se registró un mayor gasto comparado con los gobiernos panistas, sin embargo, esto resultó estadísticamente significativo sólo en el modelo M1. En el caso del M2, aunque conserva el signo esperado, la diferencia deja de ser significativa. Los resultados de los gobiernos perredistas presentan signos opuestos y sin efectos significativos. Finalmente, se observa que los gobiernos con coalición electoral PAN-PRD presentaron niveles de sobreejercicio superiores a los gobiernos panistas, en promedio, 802.4 pesos más por habitante. Queda como tarea pendiente analizar qué es lo que sucede en este tipo de gobiernos, los cuales comienzan a ser más recurrentes. ${ }^{58}$ Además, resultan de relevancia teórica para analizar cómo se comportan con respecto a las decisiones de gasto en general y en temas más específicos, como el gasto social.

En relación con el periodo electoral, se obtuvo el signo esperado: se observa que en estos años los gobiernos gastan

58 Pueden mencionarse los siguientes casos: Baja California, 20132019; Chiapas, 2000-2006; Durango, 2016-2022; Nayarit, 1999-2005; 2017 2023; Oaxaca, 2010-2016; Puebla, 2011-2017; Quintana Roo, 2016-2022; Sinaloa, 2011-2016; Veracruz, 2016-2018; y Yucatán, 2001-2007. 
en promedio 22.2 pesos más por habitante en comparación con el resto de los años, sin embargo, esta diferencia no resultó estadísticamente significativa. Por lo tanto, la H3 no pudo confirmarse.

La capacidad de gastar más de lo presupuestado implica contar con recursos adicionales. Análisis previos han demostrado que una parte de estos recursos provienen de ingresos excedentes, es decir, de una recaudación mayor a la estimada. ${ }^{59}$ Pero la contratación de deuda también es otra fuente de ingresos adicionales. En efecto, los resultados muestran que hay una relación positiva entre la contratación de deuda pública y la magnitud del GNE.

\section{CONCLUSIONES Y REFLEXIONES}

Los datos de esta investigación muestran una parte importante del comportamiento del gasto público, a saber, cómo lo que se planeó en el presupuesto de egresos difícilmente tiene una aplicación exacta en la práctica. Hasta ahora, no se contaba con información sistemática y amplia sobre la brecha que existe entre el presupuesto y el gasto ejercido en los estados. Sólo había algunos datos, fotografías de ciertos momentos, pero se carecía de un panorama que permitiera conocer la magnitud del fenómeno.

En primer lugar, la información demuestra la existencia y la persistencia de esta brecha a lo largo del tiempo. La dirección de esta diferencia indica que los gobiernos estatales están ejerciendo más gasto del que se había presupuestado, y su magnitud la aleja de las buenas prácticas internacionales. Igualmente, se reveló que a lo largo del tiempo el GNE aumentó, especialmente entre 2004 y 2011. Aunque después tuvo reducciones, la diferencia entre el gasto presupuestado y el ejercido rebasa el estándar de $+-15 \%$. En esencia, el sobreejercicio es una práctica común y de magnitud considera-

${ }^{59}$ México Evalúa, op. cit. 
ble. Estos datos llenan un vacío en la investigación, ya que los estudios sólo se habían enfocado en el presupuesto o en el gasto ejercido de forma separada, sin poner atención en la diferencia entre ambos.

En segundo lugar, para explicar las variaciones en el GNE, recurrimos al argumento de la alineación partidista vertical. En México, como república federal, las diferencias y conflictos entre los niveles de gobierno son potenciales, en especial en contextos de pluralidad partidista: se espera una conducta diferente entre los gobiernos divididos y los gobiernos unificados verticales. Si el gobierno federal tiene como objetivo mantener un equilibrio fiscal, se ocupará de que los estados no gasten más de lo que presupuestan, ya que ello podría tener un efecto negativo en la economía nacional. Lograr esto depende de la alineación partidista vertical. La hipótesis propuesta fue que los estados gobernados por la oposición tendrán un mayor nivel de GNE que aquellos en manos del mismo partido del presidente. En otras palabras, el presidente sólo obtiene la cooperación de los estados gobernados por su partido. Los resultados del análisis estadístico confirmaron esta hipótesis.

Además, se consideraron dos argumentos rivales. En el caso de la ideología partidista, se comprobó que los gobiernos del PRI y del PAN-PRD tuvieron mayores niveles de GNE que los gobiernos panistas. Como ya se indicó, queda como tarea pendiente analizar con detalle qué tipo de decisiones de gasto específicas toman los gobiernos de coalición electoral PANPRD. En el caso de los ciclos electorales, si bien se confirmó que en estos periodos se ejercieron más recursos que los presupuestados en comparación con el resto de los años, la diferencia no resultó estadísticamente significativa.

También se observó que la contratación de deuda pública está relacionada de manera positiva con los niveles de GNE, es decir, una parte de los recursos que hacen posible el sobreejercicio provienen de esta fuente. Al respecto, un estudio previo demostró que en 2016 los estados obtuvieron más 
ingresos de los estimados, y que el $86 \%$ de ellos se obtuvieron de la contratación de deuda pública. ${ }^{60}$

Por supuesto, de los resultados anteriores se deriva una agenda pendiente de investigación. Aquí se mostraron datos generales del gasto total, pero es preciso dar el siguiente paso para estudiar los niveles del GNE en rubros específicos del gasto. En segundo lugar, es preciso indagar qué acontecimientos precisos hay detrás de la relación entre la alineación partidista vertical y el GNE, es decir, qué tipo de conflicto o cooperación emerge en diferentes situaciones partidistas. En tercer lugar, otras investigaciones han demostrado que el gobierno federal también ejerce más recursos en el gasto federalizado. Aquí la tarea es identificar cómo se distribuyen estas brechas entre los estados y si existen sesgos partidistas en el proceso.

\section{Bibliografía}

Argáez, Juan, "El papel moderador de los congresos locales sobre el ciclo político presupuestal oportunista en los estados mexicanos", Gestión y Política Pública, vol. 25, núm. 2 (2016), pp. 525-549.

Armesto, María y Juan Olmeda, "Oposición legislativa y patronazgo político. Gasto en empleo público de los estados en México", Región y Sociedad, núm. 71 (2018), pp. 1-27.

Auditoria Superior de la Federación, Análisis de la Deuda Pública de las Entidades Federativas y Municipios, México, Cámara de Diputados, 2011.

Benton, Allyson, "Party Leader or Party Reputation Concerns? How Vertical Partisan Alignment Reins in Subnational Fiscal Profligacy”, The Journal of Politics, vol. 81, núm. 1 (2019), pp. 201-214.

Benton, Allyson y Heidi Smith, "A Rational Partisan Explanation for Irrational (Sub) Sovereign Debt Behavior: Evidence from Municipal Mexico", Documentos de Trabajo, núm. 264, cIDE, 2014.

${ }^{60}$ IMCO, op. cit. 
Bove, Vicenzo, Georgios Efthyvoulou y Antonio Navas, "Political cycles in public expenditure: butter vs guns", Journal of Comparative Economics, vol. 45, núm. 3 (2017), pp. 582-604.

Bulman-Pozen, Jessica, "Partisan Federalism", Harvard Law Review, vol. 127, núm. 4 (2014), pp. 1077-1146.

Busmail, Alfredo y Juan MiÑo, "Estrategias partidistas y cooperación entre niveles de gobierno durante la presidencia de Felipe Calderón”, en Nicolas Loza e Irma Méndez (coords.), Poderes y democracias. La política subnacional en México, Ciudad de México: Flacso-IEDF, 2016, pp. 113-130.

Carpizo, Carlos "Los efectos cruzados de la competencia política sobre el endeudamiento: un análisis empírico de la deuda estatal en México, 2003-2010”, trabajo presentado durante el Premio Nacional de Finanzas Públicas 2012, Cámara de Diputados, 2012. Consejo Nacional de Población, conapo, "Estimaciones y proyecciones de la población por entidad federativa" (en línea), http://www.conapo.gob.mx/es/CONAPO/Proyecciones_ Datos (consulta del 25 de mayo de 2018).

Dalen, Hendrik y Otto Swank, "Government spending cycles: Ideological or opportunistic?”, Public Choice, vol. 89, núms. 1-2 (1996), pp. 193-200.

Díaz-Cayeros, Alberto y Beatriz Magaloni (1998), "Autoridad presupuestal del poder legislativo en México: una primera aproximación”, Política y Gobierno, vol. 5, núm. 2 (1998), pp. 503-528.

Flamand, Laura, "El juego de la distribución de recursos en un sistema federal. La influencia del gobierno dividido verticalmente en la asignación de fondos federales a los estados mexicanos", Política y Gobierno, vol. 13, núm. 2 (2006), pp. 315-359.

Franzese, Robert, "Electoral and Partisan Cycles in Economic Policies and Outcomes", Annual Review of Political Science, vol. 5 (2002), pp. 369-421.

GÁmez, Cesáreo y Alejandro IbARRA-YÚnez, "El ciclo político oportunista y el gasto de los estados mexicanos", Gestión y Política Pública, vol. 18, núm. 1 (2009), pp. 39-65.

Garman, Christopher, Stephan Haggard y Eliza Willis, "Fiscal Decentralization: A Political Theory with Latin American Cases”, World Politics, vol. 53, núm. 2 (2001), pp. 205-236. 
Gutiérrez, Paola, El poder de los gobernadores en México 2001-2012: limites institucionales y políticos a nivel subnacional, tesis de doctorado, México, Flacso, 2013.

Hartmann, Sebastian, Partisan Policy-Making in Western Europe. How Ideology Influences the Content of Government Policies, Mannheim, Springer, 2015.

Herwartz, Helmut y Bernd Theilen, "Partisan influence on social spending under market integration, fiscal pressure and institutional change", European Journal of Political Economy, vol. 34 (2014), pp. 409-424.

Hibss, Douglas, "Political Parties and Macroeconomic Policy", The American Political Science Review, vol. 71, núm. 4 (1977), pp. 1467-1487.

IBARRA, Jorge, "Entorno político y dependencia financiera de los estados mexicanos", Gestión y Política Pública, vol. 22, núm. 1 (2013), pp. 3-44.

Instituto Mexicano para la Competitividad, La caja negra del gasto público, México, Iмco, 2010.

Instituto Mexicano para la Competitividad, Imco, "Índice de Información del Ejercicio del Gasto 2017” (en línea), https:/ /imco. org. $\mathrm{mx} /$ temas/indice-de-informacion-del-ejercicio-del-gasto-2017/ (consulta del 25 de mayo de 2018).

Instituto Nacional de Estadística y Geografía, INEGI, "Estadística de finanzas públicas estatales y municipales" (en línea), http:// www.inegi.org.mx/sistemas/olap/Proyectos/bd/continuas/finanzaspublicas $/$ FPMun.asp?s=est\&c=11289\&proy=efipem fmun (consulta del 25 de mayo de 2018).

Jones, Mark, Pablo Sanguinetti y Mariano Tommasi, "Politics, institutions, and fiscal performance in a federal system: an analysis of the Argentine provinces", Journal of Development Economics, vol. 61, núm. 2 (2000), pp. 305-333.

Katsimi, Margarita y Vassilis Sarantides, "Do elections affect the composition of fiscal policy in developed, established democracies?”, Public Choice, vol. 151, núm. 1 (2012), pp. 325-362.

Kinto, Manuel, “¿Por qué se endeudan los gobiernos estatales en México? Algunas consideraciones para la reforma constitucional y la ley reglamentaria en materia de responsabilidad ha- 
cendaria”, Premio Nacional de Finanzas Públicas 2014, Ciudad de México, Cámara de Diputados, 2014.

Krause, George y Ann Bowman, "Adverse Selection, Political Parties, and Policy Delegation in the American Federal System", The Journal of Law, Economics E Organization, vol. 21, núm. 2 (2005), pp. 359-387.

Kwon, Hyeok y Jonas Pontusson, "Globalization, labour power and partisan politics revisited", Socio-Economic Review, vol. 8, núm. 2 (2010), pp. 251-281.

Lennox, Anna, "A Little Help from My Friends: The Partisan Factor and Intergovernmental Negotiations in Canada", Publius:The Journal of Federalism, vol. 43, núm. 4 (2012), pp. 701-727.

Loftis, Matt y Peter Mortensen, "A new approach to the study of partisan effects on social policy", Journal of European Public Policy, vol. 24, núm. 6 (2017), pp. 890-911.

México Evalúa, Descifrando la caja negra del gasto, México, México Evalúa, 2014.

México Evalúa, Arquitectura del Ramo 23, México, México Evalúa, 2018.

México Evalúa-cidac, Léase si quiere gobernar (en serio), México, México Evalúa-CIDAC, 2018.

Montemayor, Óscar, "Determinantes del endeudamiento subnacional. Un estudio para los estados y municipios de México, 1993-1999”, Ensayos, vol. 22, núm. 1 (2003), pp. 35-88.

Nacif, Benito, Para entender el Poder Legislativo de los Estados Unidos Mexicanos, México, Nostra, 2005.

Naciones Unidas, Informe de los Objetivos de Desarrollo Sostenible 2017, Nueva York, ONU, 2017, p. 52, https://unstats.un.org/sdgs/files/report/2017/TheSustainableDevelopmentGoalsReport2017_Spanish.pdf (consulta del 25 de mayo de 2018).

Nordhaus, William, "The Political Business Cycle", The Review of Economic Studies, vol. 42, núm. 2, 1975, pp. 169-190.

NúÑEz, Leonardo, ¿ $Y$ dónde quedó la bolita? Presupuesto de Egresos ficticio, México, Aguilar, 2017.

Potrafke, Niklas, "The growth of public health expenditures in OECD countries: Do government ideology and electoral motives matter?”, Journal of Health Economics, vol. 29, núm. 6 (2010), pp. 797-810. 
Potrafke, Niklas, "Does government ideology influence budget composition? Empirical evidence from OECD countries", Economics of Governance, vol. 12, núm. 2, (2011), pp. 101-134.

Programa de Gasto Público y Rendición de Cuentas, Federal Public Financial Management Performance. Base on the PEFA Methodology, 2009, https:/ / pefa.org/country/brazil (consulta de mayo de 2018). Programa de Gasto Público y Rendición de Cuentas, Province of Santa Fe. Republic of Argetina. Public Financial Management Assessment, 2012 (en línea), https://pefa.org/assessment/ar-santa-fe-province-jul12-pfmpr-sn-public-en (consulta de mayo de 2018).

Programa de Gasto Público y Rendición de Cuentas, Marco de referencia para la evaluación de la gestión de las finanzas públicas, 2016 (en línea), https://pefa.org/sites/default/files/PEFA\%20Framework_Spanish.pdf (consulta de mayo de 2018).

Programa de Gasto Público y Rendición de Cuentas, Evaluación PEFA Colombia 2015. Desempeño de la Gestión de las Finanzas Públicas, 2016 (en línea), https://pefa.org/country/colombia (consulta de mayo de 2018).

Ramírez, Roberto y Alfredo ERQuizio, "Análisis del ciclo político electoral a partir de variables de gasto público por entidad federativa en México, 1993-2009", Paradigma económico, vol. 4, núm. 2 (2012), pp. 5-27.

READ, James, "Constitutionalizing the Dispute: Federalism in Hyper-Partisan Times", Publius: The Journal of Federalism, vol. 46, núm. 3 (2016), pp. 337-365.

Riker, William, Federalism: Origin, Operation, Significance, Boston, Little, Brown and Co., 1964.

Riker, William y Ronald Schaps, "Disharmony in Federal Government”, Behavioral Science, vol. 2 (1957), pp. 276-289.

Rodden, Jonathan, "Creating a More Perfect Union: Political Parties and the Reform of Federal Systems" (manuscrito), Departamento de Ciencia Política, MIt, 2001.

Rodden, Jonathan y Erik Wibbels, "Beyond the Fiction of Federalism. Macroeconomic Management in Multitiered Systems", World Politics, vol. 54, núm. 4 (2002), pp. 494-531.

RoldÁn, Nayeli, Miriam CASTILlo y Manuel Ureste, La estafa maestra. Graduados en desaparecer el dinero público, México, Planeta, 2018. 
SÁEz, Lawrence y Aseema Sinha, "Political Cycles, Political Institutions and Public Expenditures in India, 1980-2000", British Journal of Political Science, vol. 40, núm. 1 (2009), pp. 91-113.

Sakurai, Sergio y Naercio Menezes, "Opportunistic and partisan election cycles in Brazil: new evidence at the municipal level", Public Choice, vol. 148, núms. 1-2 (2010), pp. 233-247.

Schmitт, Carina, "Panel data analysis and partisan variables: how periodization influence partisan effects", Journal of European Public Policy, vol. 23, núm. 10 (2016), pp. 1442-1459.

Shi, Min y Jakob Svensson, "Political Budget cycles: Do they differ across countries and why?", Journal of Public Economics, vol. 90, núms. 8-9 (2006), pp. 1367-1389.

Sleman, Fanny, El poder presupuestal de los gobernadores en México (2000-2012): la influencia de las reglas presupuestales y del pluralismo legislativo, tesis de doctorado, México, Flacso, 2014.

Tépach, Reyes, "La deuda pública de las entidades federativas explicada desde la perspectiva del federalismo mexicano", Documento de trabajo, Cámara de Diputados, 2012, http://www. diputados.gob.mx/sedia/sia/se/SAE-ISS-17-12.pdf (consulta del 25 de mayo de 2018).

TÉPAch, Reyes, "El flujo de deuda pública de las entidades federativas de México analizado desde el enfoque del federalismo fiscal”, Documento de trabajo, Cámara de Diputados, 2015, http:/ / www.diputados.gob.mx/sedia/sia/se/SAE-ISS-15-15.pdf (consulta del 25 de mayo de 2018).

Trejo, Guillermo y Sandra Ley, "Federalismo, drogas y violencia. Por qué el conflicto partidista intergubernamental estimuló la violencia del narcotráfico en México”, Política y Gobierno, vol. 23, núm. 1 (2016), pp. 11-56.

Ugalde, Carlos (coord.), La negociación política del presupuesto en México 1997-2012, México, edimpro-sitesa, 2014.

VelázQuez, César, "Determinantes del gasto estatal en México", Gestión y Política Pública, vol. 15, núm. 1 (2006), pp. 83-108.

Vergne, Clémence, "Democracy, elections and allocation of public expenditures in development countries", European Journal of Political Economy, vol. 25, núm. 1 (2009), pp. 63-77. 